\title{
Oxytocin versus Methylergometrine in the Active Management of Third Stage of Labour
}

\author{
Ajantha Boopathi ${ }^{*}$, Sujir Radhakrishnan Nayak², Arun Rao², Bharathi Rao² \\ ${ }^{1}$ Andal Hospital, Cuddalore, India \\ ${ }^{2}$ Department of Obstetrics and Gynecology, Kasturba Medical College (A Constituent of Manipal University), \\ Mangalore, India \\ Email: ${ }^{*}$ drajantha2010@gmail.com
}

Received 19 June 2014; revised 15 July 2014; accepted 10 August 2014

Copyright (C) 2014 by authors and Scientific Research Publishing Inc.

This work is licensed under the Creative Commons Attribution International License (CC BY). http://creativecommons.org/licenses/by/4.0/

(c) (i) Open Access

\begin{abstract}
Objective: To compare the efficacy of Oxytocin versus Methylergometrine in active management of third stage of labour in reducing risk of postpartum hemorrhage. Methods: This study was carried out by randomly assigning into two groups with 150 women in each group. Group 1 included patients who received injection Oxytocin $10 \mathrm{IU}$ intramuscular within one minute of the birth of the baby. Injection Methylergometrine $(0.2 \mathrm{mg})$ was given intravenously at the delivery of anterior shoulder of the baby to women in Group 2. Outcome measures were the duration of third stage, blood loss, pre and post-delivery hematocrit, side effects and incidence of PPH. Statistical analysis was done using Chi square test, Fischers test, Mann Whitney test, and t test. $p<0.05$ was considered significant. Results: Mean duration of third stage of labour, mean blood loss, post-delivery fall in hematocrit and need for additional uterotonics were significantly less in the Group 2. However side effects like nausea, vomiting and rise in blood pressure were significantly higher in women in Group $2(p=0.000)$. Conclusion: Methylergometrine is more effective than oxytocin in reducing the duration of third stage of labour and blood loss but has significant side effects like nausea, vomiting and rise in blood pressure.
\end{abstract}

\section{Keywords}

AMTSL-Active Management of Third Stage of Labour, DBP-Diastolic Blood Pressure, PCV—Packed Cell Volume, PPH—Post Partum Hemorrhage, SBP-Systolic Blood Pressure

\section{Introduction}

Postpartum haemorrhage (PPH) or excessive bleeding after child birth is the single most important direct cause

"Corresponding author.

How to cite this paper: Boopathi, A., Nayak, S.R., Rao, A. and Rao, B. (2014) Oxytocin versus Methylergometrine in the Active Management of Third Stage of Labour. Open Journal of Obstetrics and Gynecology, 4, 666-671.

http://dx.doi.org/10.4236/ojog.2014.411093 
of maternal deaths in developing countries [1]. According to WHO, there are about 14 million cases of obstetric haemorrhage each year [2]. Over one hundred thousand of these women die within a few hours after childbirth and many more experience long term morbidity. We have followed research developments in the area of prevention and treatment of postpartum haemorrhage in the last decade with interest. The fact that contractions of the uterus are necessary to prevent bleeding after placental separation has been known for centuries, so attempts to devise interventions to facilitate this process are a logical quest. The active management of third stage of labour (AMTSL), consists of three interlocking components which include administering an uterotonic drug, assisting with the delivery of the placenta by controlled cord traction, and massaging the uterus after the placental delivery [3]-[6].

Fortunately, research has demonstrated the effectiveness of active management of third stage of labour (AMTSL) as a feasible and low cost intervention to prevent PPH [4]. It is estimated that AMTSL can eliminate more than half of PPH cases potentially saving thousands of women's lives. The active management of third stage of labour is a combination of actions to speed the delivery of placenta and prevent postpartum haemorrhage.

The objective of prophylactic oxytocics is to ensure efficient contraction of the uterus after delivery of neonate, thus minimizing the amount of blood loss due to failure of occlusion of capillaries in placental site, and promote rapid separation and descent of the placenta.

Uterotonic drugs studied in the AMTSL include Oxytocin, Methylergometrine, Syntometrine, Prostaglandin analogues in varying doses and different routes of administration with different results [7]-[12].

This randomized study was conducted to compare Methylergometrine and Oxytocin in terms of efficacy, duration of third stage, blood loss, reduction in incidence of postpartum hemorrhage, effect on hematocrit, blood pressure and other side effects.

\section{Materials and Methods}

This randomised prospective comparative study was conducted between April 2012-January 2013 on 300 women, who were admitted in labour ward and in women who entered active phase of labour spontaneously with no known risk factors for PPH. Institutional Ethics Committee approval was obtained. All patients included in the study delivered vaginally. A sample size of 300 women with $95 \%$ confidence level and $80 \%$ power was needed to detect significant change in the post partumhemorrhage.

The eligible women who gave informed consent were assigned to 2 groups at a random of 150 in each group. Women with even inpatient number were allotted to Group 1 and odd inpatient number allotted to Group 2.

Group 1 included women who received injection Oxytocin 10 IU intramuscular within one minute of the birth of the baby. Group 2 comprised women who received injection methyl-ergometrine $0.2 \mathrm{mg}$ intravenous at the delivery of anterior shoulder of the baby.

Inclusion criteria were singleton term cephalic pregnancies, spontaneous onset of labour, no contraindication for Oxytocin/Methylergometrine and no known risk factor for PPH.

Women who had operative deliveries, multiple pregnancy, intrauterine death, Rh immunisation, hypertension in pregnancy, Anemia-Hb $<9$ gram\% (ICMR classification), heart disease, past history of third stage complications. Previous caesarean section, disorders of blood coagulation were excluded from the study.

The delivery was effected with the patient at the edge of the table, either 10 IU of injection Oxytocin intramuscular within one minute of the birth of the baby or injection Methylergometrine $0.2 \mathrm{mg}$ intravenous given at the delivery of anterior shoulder of the baby in a randomised order. Once the baby is delivered, apex of the episiotomy was sutured. Haemostatic clamps applied on the bleeders. Placenta is delivered by controlled cord traction and time taken for placental separation was noted with a stopwatch.

Controlled cord traction was done by clamping the cord close to the perineum and held in one hand, the other hand is placed above the pubic symphysis and the uterus is stabilised by applying counter pressure. Slight tension is kept on the cord awaiting a strong uterine contraction $(2-3 \mathrm{~min})$. If the placenta does not descend in 30 $40 \mathrm{sec}$ of controlled cord traction, traction on the cord is not given. The cord is held gently awaiting a strong uterine contraction again. With the next contraction controlled cord traction is repeated with counter traction. Once the placenta is delivered, the patient was placed over a blood drape (BRASS V drape) (Figure 1), which is a disposable, conical, graduated plastic collection bag. Blood loss was measured after one hour. If there was profuse bleeding following episiotomy, such women were excluded from the study. 


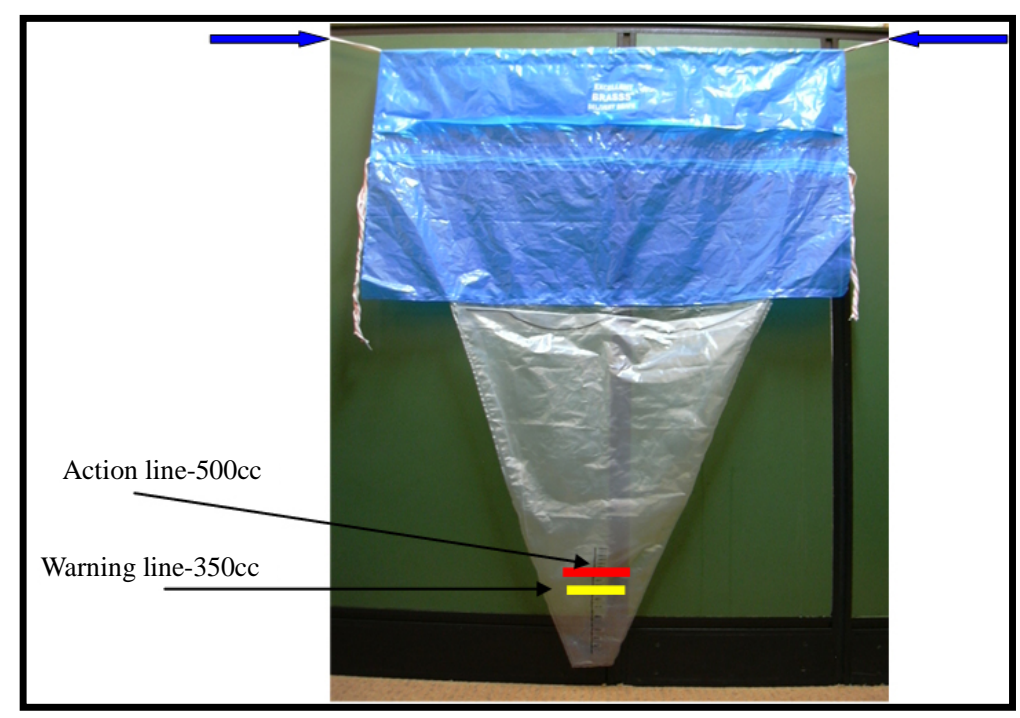

Figure 1. BRASS V drape.

Outcome measures were incidence of postpartum hemorrhage (blood loss more than $500 \mathrm{ml}$ ), pre-delivery and post-delivery hematocrit, need for additional uterotonics, blood transfusion, side effects like nausea, vomiting and high blood pressure.

The collected data was analysed by frequency, percentage, Chi square test, Fischer exact test, Mann Whitney test, Student paired and unpaired t test. $\mathrm{p}<0.05$ was considered significant. All statistical analysis was performed using SPSS Version 13.0 software.

\section{Results}

There were no significant differences in mean age, parity, gestational age at delivery but mean birth weight was more in the Methylergometrine group p $=0.049$ (Table 1). Mean duration of third stage of labour, mean blood loss and fall in packed cell volume were significantly less in the Methylergometrine group as shown in (Table 2). Methylergometrine was associated with significant side effects like nausea, vomiting and increase in both systolic and diastolic blood pressure $\mathrm{p}=0.000$ (Table 3). Blood loss more than $500 \mathrm{ml}$ was found in $6.7 \%$ and $2.7 \%$ in the Oxytocin and Methylergometrine groups, respectively which was statistically significant and 7.3\% in the Oxytocin group needed additional uterotonic whereas only $2 \%$ in the Methylergometrine required additional uterotonic $(\mathrm{p}=0.029)$. However there were no statistically significant differences in the need for blood transfusion in both the groups (Table 4).

\section{Discussion}

This randomised prospective study compares the efficacy of Oxytocin versus Methylergometrine in the active management of third stage of labour. PPH is a significant contributor to severe maternal morbidity and longterm disability as well as to a number of other severe maternal conditions generally associated with more substantial blood loss, including shock and organ dysfunction [3].

Post-partum haemorrhage (PPH) is an important cause of maternal morbidity and mortality, especially in developing countries. The prophylactic use of oxytocics in the third stage of labour has been found to decrease the rate of post partum bleeding. However, there is no agreement regarding the type and route of administration of oxytocic drugs which offers the best efficacy and safety profile. A randomised prospective study [13] was carried out on 600 women. The women allocated under Oxytocin group $n=297$ were given 10 IU Oxytocin intravenously at delivery of the anterior shoulder, while in the ergometrine group $n=303$ the women were given $0.25 \mathrm{mg}$ of ergometrine intravenously at delivery of the anterior shoulder. The average age in Oxytocin group was $27.09 \pm 6.17$ (18 - 40 years), while in ergometrine group it was $27.05 \pm 6.07$ (18 - 42 years). The duration of third stage of labour was $5.88 \pm 1.26$ (range $3-10 \mathrm{~min}$.) in Oxytocin group and $6.46 \pm 2.01$ (range 3 - $15 \mathrm{~min}$ ) in the ergometrine group ( $\mathrm{p}$ value $=0.06$ ). The rate of estimated blood loss in millilitres was $245.66 \pm 95.43$ (range 
Table 1. Demographic profile of women.

\begin{tabular}{cccc}
\hline Characteristics & Group 1 $(\mathbf{n}=\mathbf{1 5 0})$ & Group $\mathbf{2}(\mathbf{n}=\mathbf{1 5 0})$ & Statistical analysis \\
\hline Age, years & $25.92 \pm 3.55$ & $26.19 \pm 4.06$ & $\mathrm{t}=0.604$ \\
Range & $18-39$ & $18-40$ & $\mathrm{p}=0.546$ \\
Parity & & & $\mathrm{p}=0.726$ \\
Primi & $88(58.7 \%)$ & $85(56.7 \%)$ & $\mathrm{t}=0.222$ \\
Multi & $62(41.3 \%)$ & $65(43.3 \%)$ & $\mathrm{p}=0.825$ \\
Gestational age & $38.87 \pm 0.78$ & $38.85 \pm 0.78$ & $\mathrm{t}=1.974$ \\
(weeks) & $37-40$ & $37-40$ & $\mathrm{p}=0.049^{*}$ \\
Range & $2.81 \pm 0.34$ & $2.89 \pm 0.37$ & $1.8-4.0$ \\
Birth weight (kg) & $2.0-4.0$ & & \\
Range & &
\end{tabular}

Values are given as means \pm SD unless otherwise indicated; ${ }^{*}$ Significant at $\mathrm{p}<0.05$.

Table 2. Duration of third stage and blood loss.

\begin{tabular}{lccc}
\hline \multicolumn{1}{c}{ Characteristics } & Group 1 $(\mathbf{n}=\mathbf{1 5 0})$ & Group $2(\mathbf{n}=\mathbf{1 5 0})$ & Statistical analysis \\
\hline Duration of third stage, minutes & $3.45 \pm 2.75$ & $2.31 \pm 1.06$ & $\mathrm{t}=4.727$ \\
Range & $1-28$ & $1-7$ & $\mathrm{p}=0.001^{*}$ \\
Measured blood loss by calibrated drapes (milliliters) & $196.57 \pm 192.30$ & $149.33 \pm 145.47$ & $\mathrm{z}=2.925$ \\
Range & $25-1200$ & $25-1300$ & $\mathrm{p}=0.000^{*}$ \\
Predelivery PCV & $31.61 \pm 2.89$ & $32.43 \pm 2.89$ & $\mathrm{t}=3.641, \mathrm{p}=0.000^{*}$ \\
Postdelivery PCV & $29.71 \pm 2.54$ & $31.09 \pm 3.12$ & \\
\hline
\end{tabular}

Values are given as mean \pm SD unless otherwise indicated; "Significant at $\mathrm{p}<0.05$.

Table 3. Associated side effects in the two groups.

\begin{tabular}{cccc}
\hline Variable & Group 1 (n= 150) & Group 2 (n= 150) & Statistical analysis \\
\hline Nausea and vomiting & $0(0 \%)$ & $10(6.7 \%)$ & $\chi^{2}=10.345, \mathrm{p}=0.001^{*}$ \\
Elevated blood pressure & & $116.17 \pm 6.22$ \\
SBP before delivery & $117.96 \pm 6.80$ & $131.59 \pm 4.36 \quad \mathrm{t}=24.197, \mathrm{p}=0.000^{*}$ \\
SBP after delivery & $119.23 \pm 7.13$ & $78.05 \pm 4.91$ & $\mathrm{t}=23.28, \mathrm{p}=0.000^{*}$ \\
DBP before delivery & $75.96 \pm 5.58$ & $93.52 \pm 3.79 \quad$ &
\end{tabular}

Values are given as mean \pm SD unless otherwise indicated; *Significant at $\mathrm{p}<0.05$; Blood pressure measured in mm Hg.

Table 4. Post delivery complications in the two groups.

\begin{tabular}{cccc}
\hline Variable & Group $\mathbf{1}(\mathbf{n}=\mathbf{1 5 0})$ & Group $\mathbf{2}(\mathbf{n}=\mathbf{1 5 0})$ & Statistical analysis \\
\hline Postpartum hemorrhage & $10(6.7 \%)$ & $4(2.7 \%)$ & $\mathrm{Z}=1.69, \mathrm{p}=0.047^{*}$ \\
Need for additional uterotonic & $11(7.3 \%)$ & $3(2 \%)$ & $\chi^{2}=4.795, \mathrm{p}=0.029^{*}$ \\
Need for blood transfusion & $2(1.3 \%)$ & $1(0.66 \%)$ & $\mathrm{Z}=0.580, \mathrm{p}=0.281$ \\
\hline
\end{tabular}

"Significant at $\mathrm{p}<0.05$.

$200-600 \mathrm{ml}$ ) in Oxytocin group, where as it was $246.58 \pm 77.6$ (range $100-700 \mathrm{ml}$ ) in the ergometrine group (p value $=0.940)$.

In the present study there was no statistically significant difference between the two groups with regard to maternal age and parity. $84.7 \%$ of cases in the Oxytocin group and $80.0 \%$ of cases in the Methylergometrine group were ranging from the age group of 21 - 30 years. The mean duration of third stage was $3.45 \pm 2.75$ in Oxytocin group (range $1-28 \mathrm{~min}$ ) and $2.31 \pm 1.06$ (range $1-7 \mathrm{~min}$ ) in the Methylergometrine group (p value $<$ 
0.001). The mean blood loss was $196.57 \pm 192.30$ (range 25 - $1200 \mathrm{ml}$ ) in Oxytocin group and $149.33 \pm 145.47$ (range $25-1300 \mathrm{ml}$ ) in the Methylergometrine group. The difference in mean blood loss between the two groups was $47.24 \mathrm{ml}$ with p value of 0.003 .

In a study [14] carried out on 583 women with singleton pregnancy and normal vaginal delivery were randomly allocated to receive syntometrine $(n=293)$ or Oxytocin $(n=290)$. Oxytocin augmentation was used in 200 women (68\%), and 198 women (68\%) in syntometrine and Oxytocin groups respectively. Episiotomy was performed in 250 women (85\%) in syntometrine group and 260 women (90\%) in Oxytocin group. The mean birth weight of the baby in both groups was $3.2 \mathrm{~kg}$.

In our study all the 300 women had spontaneous onset of labour and were not augmented with Oxytocin. Episiotomy was performed in 134 women (89.3\%) in the Oxytocin group and 132 women (88\%) in the Methylergometrine group. The mean birth weight of the baby in both groups was $2.8 \mathrm{~kg}$.

In the randomised comparative study [13] of prophylactic Oxytocin versus ergometrine in the third stage of labour, $6.9 \%$ of the women had retained placenta in the ergometrine group and $4.1 \%$ in the Oxytocin group, but none of the patients had retained placenta in our study. 9.9\% in the ergometrine group and $6.1 \%$ in the Oxytocin group needed additional oxytocics [13]. In the present study only $2 \%$ in the Methylergometrine group and $7.3 \%$ in the Oxytocin group needed additional oxytocics. $43.6 \%$ in the ergometrine group and $5.1 \%$ in the Oxytocin group had side effects like nausea and vomiting [13]. In the present study 6.7\% in the Methylergometrine group and none of the patients in the Oxytocin group had the side effects.

The pre delivery hematocrit range in the ergometrine group was $35.73 \pm 2.11$ and $35.95 \pm 2.07$ in the Oxytocin group [13]. In the present study pre delivery hematocrit was $32.43 \pm 2.89$ in the Methylergometrine group and $31.61 \pm 2.89$ in the Oxytocin group. The post delivery hematocrit was $31.28 \pm 2.26$ in the ergometrine group and $31.70 \pm 2.21$ in the Oxytocin group with p value of 0.185 [13]. In the present study the post delivery hematocrit in the Methylergometrine group was $31.09 \pm 3.12$ and $29.71 \pm 2.54$ in the oxytocin group with p value of $<0.001$. Measurement of hematocrit before and after delivery is a more objective method in assessing the amount of blood loss. It is also clinically more important and relevant as it aids the decision for further effective management.

\section{Conclusion}

Methylergometrine and Oxytocin have been used for a long time in markedly different doses and routes of administration with varying success. The use of Methylergometrine as part of AMTSL is associated with statistically significant reduction in duration of third stage of labour, mean blood loss, need for additional uterotonics when compared to Oxytocin but has significant side effects like nausea, vomiting and rise in blood pressure. The choice of drug depends on cost, facilities for storage and refrigeration and assessment of trade-off between benefits and side-effects.

\section{Conflicts of Interest}

None.

\section{Funding}

Self funding by the corresponding author.

\section{Informed Consent Obtained from All Women in the Study Group}

Trial approved by Institutional Review Board.

\section{References}

[1] Dongol, A.S., Shrestha, A. and Chawla, C.D. (2010) Post Partum Haemorrhage: Prevalence, Morbidity and Management Pattern in Dhulikhel Hospital. Kathmandu University Medical Journal (KUMJ), 8, 212-215. http://dx.doi.org/10.3126/kumj.v8i2.3561

[2] Abou Zahr, C. (2003) Global Burden of Maternal Death and Disability. World Health Organization, Geneva, Switzerland. British Medical Bulletin, 67, 1-11. http://dx.doi.org/10.1093/bmb/ldg015

[3] World Health Organization (2012) World Health Organization Multicountry Survey on Maternal and Newborn Health. 
WHO, Geneva.

[4] Tsu, V.D., Levin, C., Tran, M.P., Hoang, M.V. and Luu, H.T. (2009) Cost-Effectiveness Analysis of Active Management of Third-Stage Labour in Vietnam. Health Policy Plan, 24, 438-444. http://dx.doi.org/10.1093/heapol/czp020

[5] Winter, C., Macfarlane, A., Deneux-Tharaux, C., Zhang, W.H., Alexander, S., Brocklehurst, P., et al. (2007) Variations in Policies for Management of the Third Stage of Labour and the Immediate Management of Postpartum Haemorrhage in Europe. BJOG, 114, 845-854. http://dx.doi.org/10.1111/j.1471-0528.2007.01377.x

[6] Festin, M.R., Lumbiganon, P., Tolosa, J.E., Finney, K.A., Ba-Thike, K., Chipato, T., et al. (2003) International Survey on Variations in Practice of the Management of the Third Stage of Labour. Bulletin of the World Health Organization, 81, 286-291.

[7] Dumoulin, J.G. (1981) A Reappraisal of the Use of Ergometrine. Journal of Obstetrics and Gynecology, 1, $178-181$. http://dx.doi.org/10.3109/01443618109067375

[8] Embrey, M.P. (1961) Simultaneous Intramuscular Injection of Oxytocin and Ergometrine: Atocographic Study. BMJ, 1, 1737-1738. http://dx.doi.org/10.1136/bmj.1.5241.1737

[9] McDonald, S., Prendville, W.J. and Elbourne, D. (2001) Prophylactic Syntometrine versus Oxytocin for Delivery of the Placenta. The Cochrane Database of Systematic Reviews, 1, Article ID: CD000201.

[10] Suellen, M., et al. (2004) A Cochrane Review Metaanalysis. New Advances for Low-Resource Settings: Uterotonics for Prevention of Postpartum Hemorrhage. Journal of Midwifery \& Women's Health, 49, 283-292. http://dx.doi.org/10.1016/j.jmwh.2004.04.001

[11] Bugalho, A., Daniel, A., Faundes, A. and Cunha, M. (2001) Misoprostol for Prevention of Postpartum Hemorrhage. International Journal of Gynecology Obstetrics, 73, 1-6. http://dx.doi.org/10.1016/S0020-7292(01)00346-0

[12] Choy, C.M., Lau, W.C., Tam, W.H. and Yuen, P.M. (2002) A Randomized Controlled Trial of Intramuscular Syntometrine and Intravenous Oxytocin in the Management of the Third Stage of Labour. BJOG, 109, 173-177. http://dx.doi.org/10.1111/j.1471-0528.2002.01204.x

[13] Orji, E., Agwu, F., Loto, O. and Olaleye, O. (2008) A Randomised Comparative Study of Prophylactic Oxytocin versus Ergometrine in the Third Stage of Labour. International Journal of Gynecology Obstetrics, 101, 129-132. http://dx.doi.org/10.1016/j.ijgo.2007.11.009

[14] Malkawi, H., Hindawi, I., Hiasat, M. and Amarin, V. (2005) Oxytocin and Syntometrine in Prevention of Postpartum Hemorrhage. JRMS, 12, 75-77. 
Scientific Research Publishing (SCIRP) is one of the largest Open Access journal publishers. It is currently publishing more than 200 open access, online, peer-reviewed journals covering a wide range of academic disciplines. SCIRP serves the worldwide academic communities and contributes to the progress and application of science with its publication.

Other selected journals from SCIRP are listed as below. Submit your manuscript to us via either submit@scirp.org or Online Submission Portal.
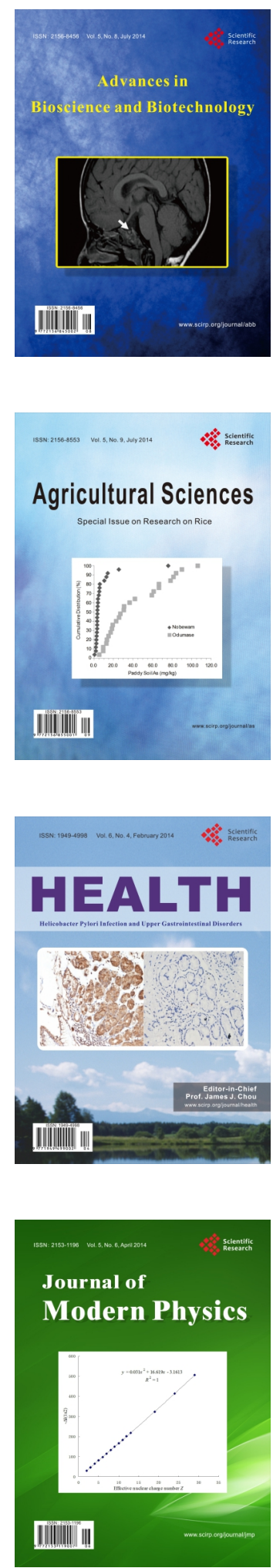
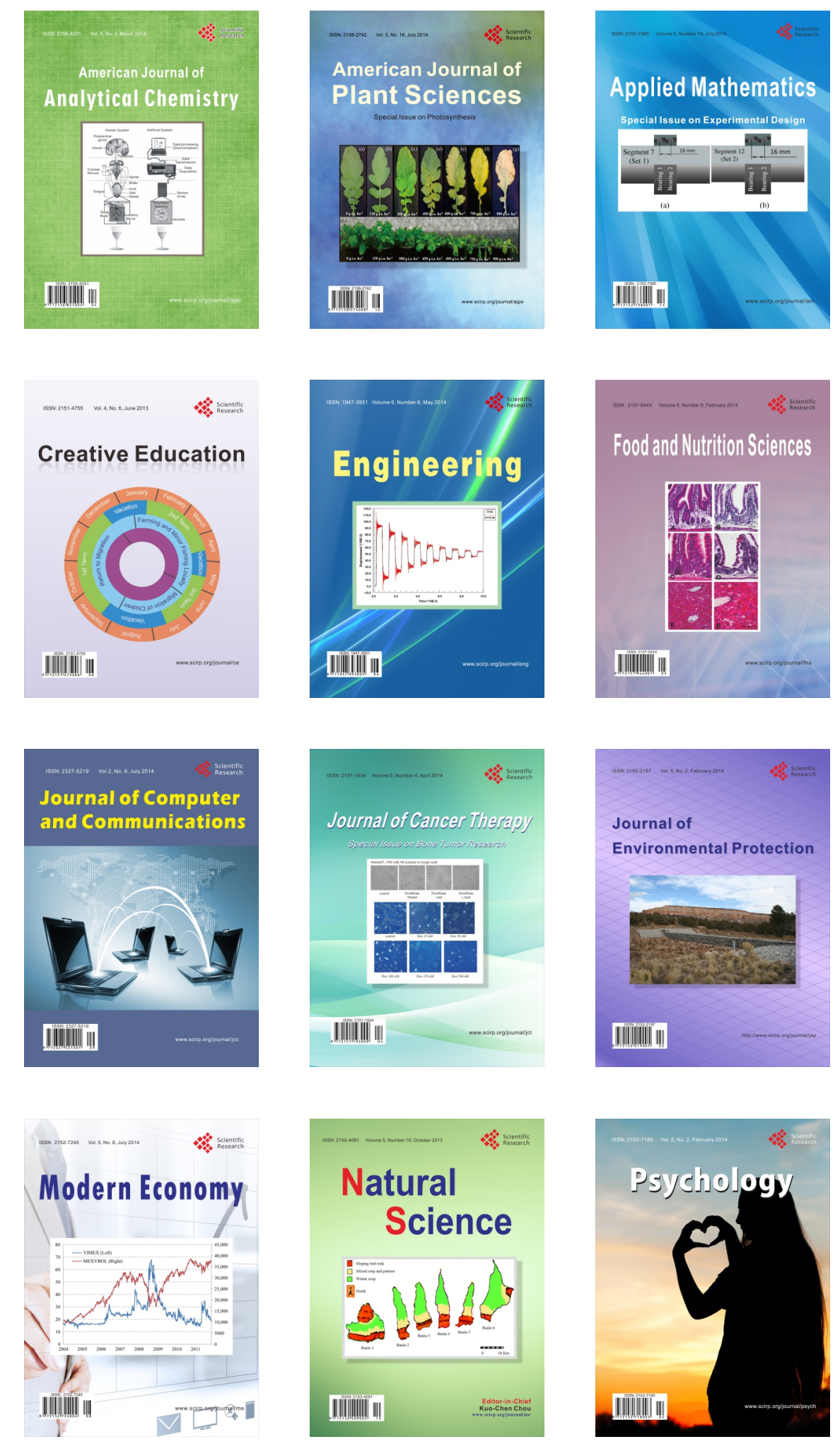